\title{
MELANOMATOSE MENINGEA: ANALISE CITOMORFOLOGICA DO LIQUIDO CEFALORRAQUEANO
}

\author{
J. A. LIVRAMENTO* \\ L. R. MACHADO** \\ H. A. M. CLEMENTE *** \\ A. TABARES-OLIVES *** \\ A. SPINA-F'RANCA ****
}

A melanomatose meníngea é afecção rara, geralmente secundária a nevos cutâneos por malignização de células produtoras e armazenadoras de melanina. Sua evolução usualmente é fulminante. O diagnóstico precoce tem importância cada vez maior, à medida em que progridem os estudos sobre a imunologia dos tumores, dado ter a melanomatose desempenhado papel importante nos avanços quanto a esses conhecimentos.

As células produtoras e armazenadoras de melanina, características do melanoma maligno, são os melanócitos. Eles são encontrados normalmente na pele, íris, corpos ciliares, coróides, retina, tecido cromatínico do sistema adrenérgico e, no sistema nervoso central ( $\mathrm{SNC}$ ), nas leptosmeninges e no locus niger $\stackrel{2}{*}$.

Cerca de $85 \%$ dos melanomas têm seu início na pele e $90 \%$ destes se localizam em nevos cutâneos benignos. Entre outros locais frequentes em que se iniciam melanomas encontram-se: olhos, orofaringe, genitais e região ano-retal 2 .

A capacidade metastatisante do melanoma é variável; em algumas ocasiões ele desenvolve metástases antes que a lesão primária seja diagnosticada. Em outros casos a evolução é mais lenta, levando até alguns anos para o aparecimento de metástases, mesmo em casos em que tenha sido extirpada a lesão primária 2.

A melanomatose maligna primitiva do SNC é bastante rara. Já as metástases meningeas do melanoma maligno cutâneo são relativamente frequentes, ocasionando então quadros de melanomatose meníngea.

O objetivo deste trabalho é analisar as características citomorfológicas do líquido cefalorraqueano (LCR) de seis pacientes com melanomatose meníngea secundária. É dada ênfase à presença de células atípicas ao LCR, pois elas constituiram o elemento chave para o diagnóstico da afecção nos seis casos registrados.

Trabalho do Centro de Investigaçóes em Neurologia da Clínica Neurológica da Faculdade de Medicina da Universidade de Săo Paulo: *Médico Assistente; **aédico Adido; **Médico Estagiário; ***Professor Adjunto. 


\section{CASUISTICA}

Caso 1 - O. N., com 56 anos, feminina, branca, registro L- 67.464. Paciente com diagnóstico de melanomatose cutânea evoluindo há cerca de 2 anos. Apresentou síndrome de hipertensão intracraniana associada a hemiparesia direita, afasia e crises convulsivas generalizadas. O LCR era limpido e incolor, normotenso, com 28 células por mm3. A população celular era constituida quase totalmente de células atípicas ao LCR: linfócitos, reticulomonócitos e sobretudo macrófagos compunham o restante do quadro citologico.

Caso 2 - M. A. S., com 35 anos, feminina, branca, registro L- 67.463. Paciente com diabetes melito que apresentou quadro de cefaléia seguido de alterações da consciência, que evoluiu rapidamente para o coma. O LCR era hemorrágico apresentando 506 leucócitos e 27.0000 hemácias por mm3. As hemácias apresentavam-se em diversos estágios de degeneraçăo. Predominavam na análise citomorfológica células atípicas ao LCR, em meio à população restante, constituida de línfócitos, retículomonócitos, polinucleares neutrófilos e macrófagos.

Caso \$ - H. A. N., com 22 anos, masculino, branco, registro L- 59.739. Apresentava queixa de prurido em nevos cutâneos, nos quais foram evidenciados sinais de malignização há um mês. Há uma semana, instalou-se paraparesia crural flácida. Ao exame do LCR lombar foram constatadas alterações das provas manométricas sugestivas da vigencia de bloqueio parcial. O LCR era limpido e xantotocromico, contendo 25 células por mmi. A população celular era composta de linfócitos, reticulomonócitos, polinucleares neutrófilos, células eosinófilas e grande contingente de células atípicas a LCR.

Caso 4 - N. S. L., com 21 anos, feminina, branca, registro L- 65.406. Paciente com sindrome de hipertensão intracraniana e sinais de irritação meníngea, que evoluiu rapidamente para coma. O LCR apresentava-se hipertenso e era hemorrágico. A citometria mostrou 12 leucócitos e 4.200 hemácias por $\mathrm{mm}$. As hemáclas encontravamse em vários estágios de degeneração. Havia grande quantidade de células atípicas ao LCR, além de raros linfócitos, reticulomonócitos, polinucleares neutrófilos e macrófagos.

Caso 5 - B. A. M., com 61 anos, masculino, branco, registro L- 66.371. Paciente apresentou hemiparesia díreita de instalação súbita, tendo sido feito diagnóstico clínico de acidente vascular cerebral. O único antecedente valorizável "a posteriori" foi o relato de retirada de um nevo cutáneo há 14 anos. O LCR era limpido e levemente xantocrómico, apresentando 33 células por mm3. Estas eram representadas por linfócitos, reticulomonócitos, polinucleares neutrófilos, macrófagos, além de grande contingente de células atípicas ao LCR.

Caso 6 - G. P., com 28 anos, masculino, branco, registro L- 37.012. Paciente com sindrome de cauda equina, que se instalou após exerese de melanoma cutaneo maligno. Submetido a punção lombar, foram evidenciadas alteraçðes discretas das provas manométricas. O LCR era límpido e levemente xantocrômico, contendo 7,3 células por mm3. A população celular era constituida de linfócitos, reticulomonócitos e raras células atípicas ao LCR. Caso registrado parcialmente em publicaçăo anterior 8.

\section{METODOS}

A citometria do material apresentado foi feita através de câmara de FuchṣRosenthal. $O$ estudo citomorfológico foi realizado pelo método de sedimentação gravitacional acelerada utilizando a câmara de Suta conforme padronização adotada 


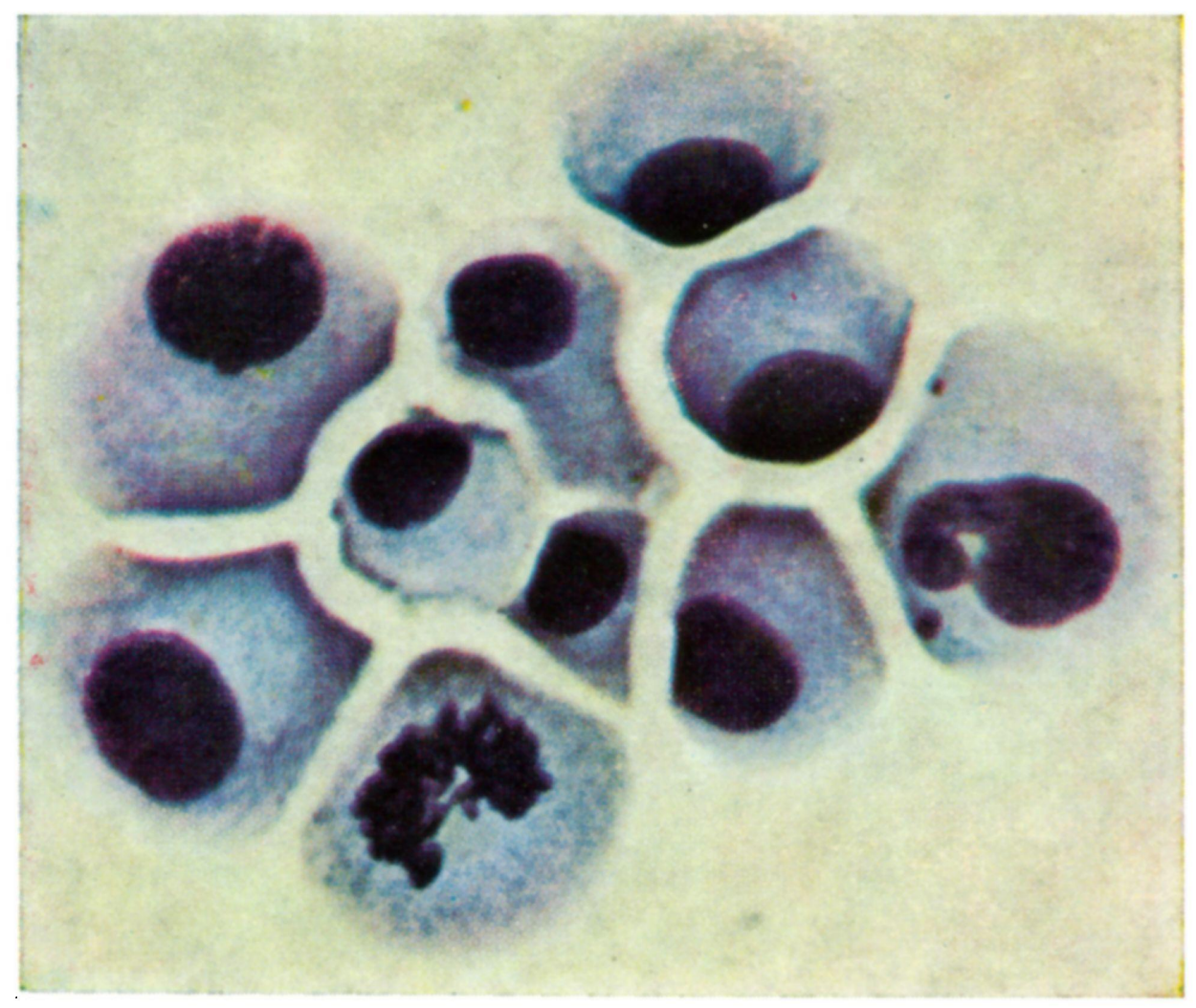

Fig. 1 - Células melanomatosas justapostas; presenca de mitose atipica (May Grünwald-Giemsa 360x).

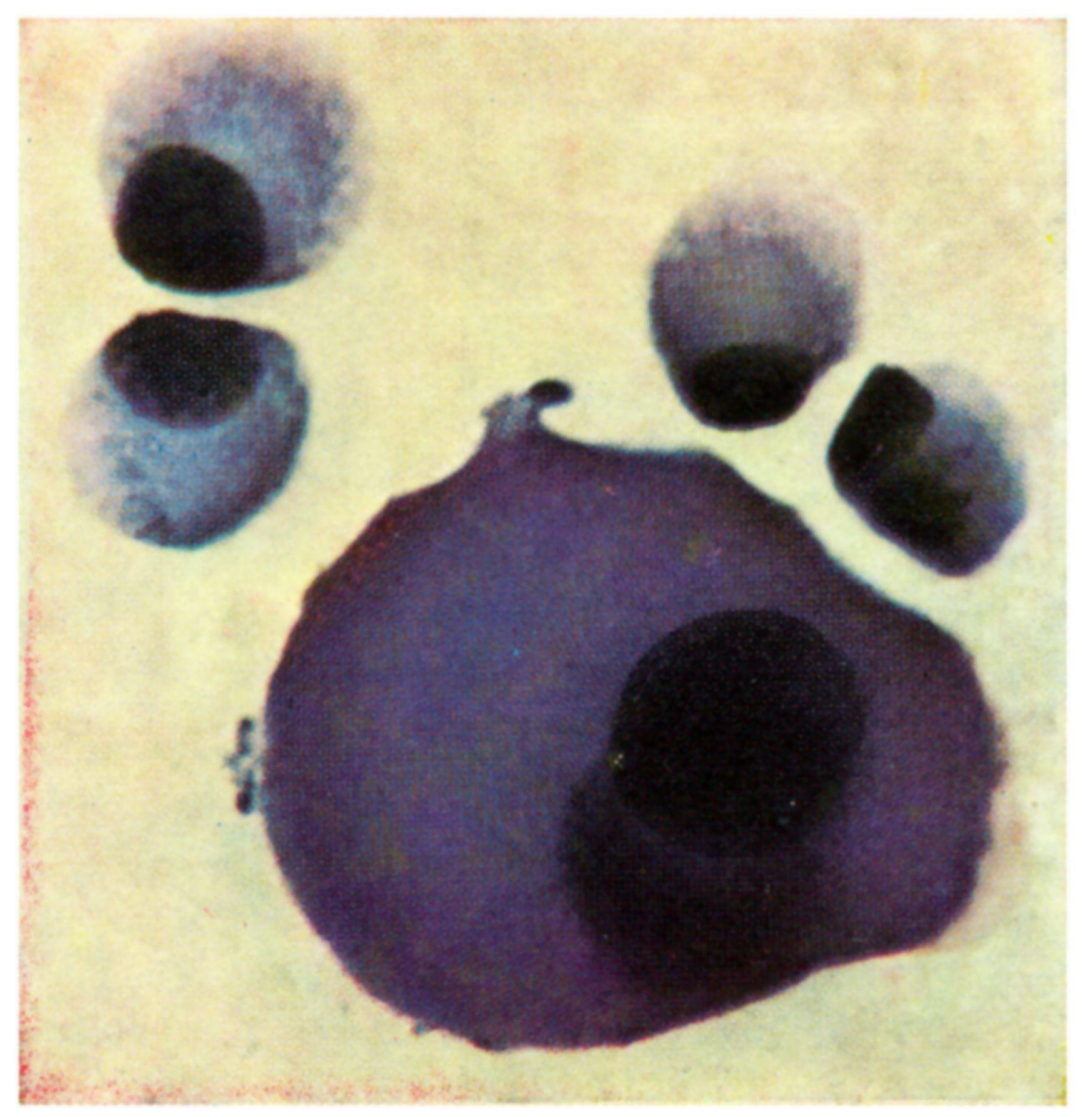

Fig. \& - Melanoblasto gigante, com basofilia citoplasmdtica intensa, ao lado de outros melaroblastos de tamanho menor (May Grïnwald-Giemsa 360x). 


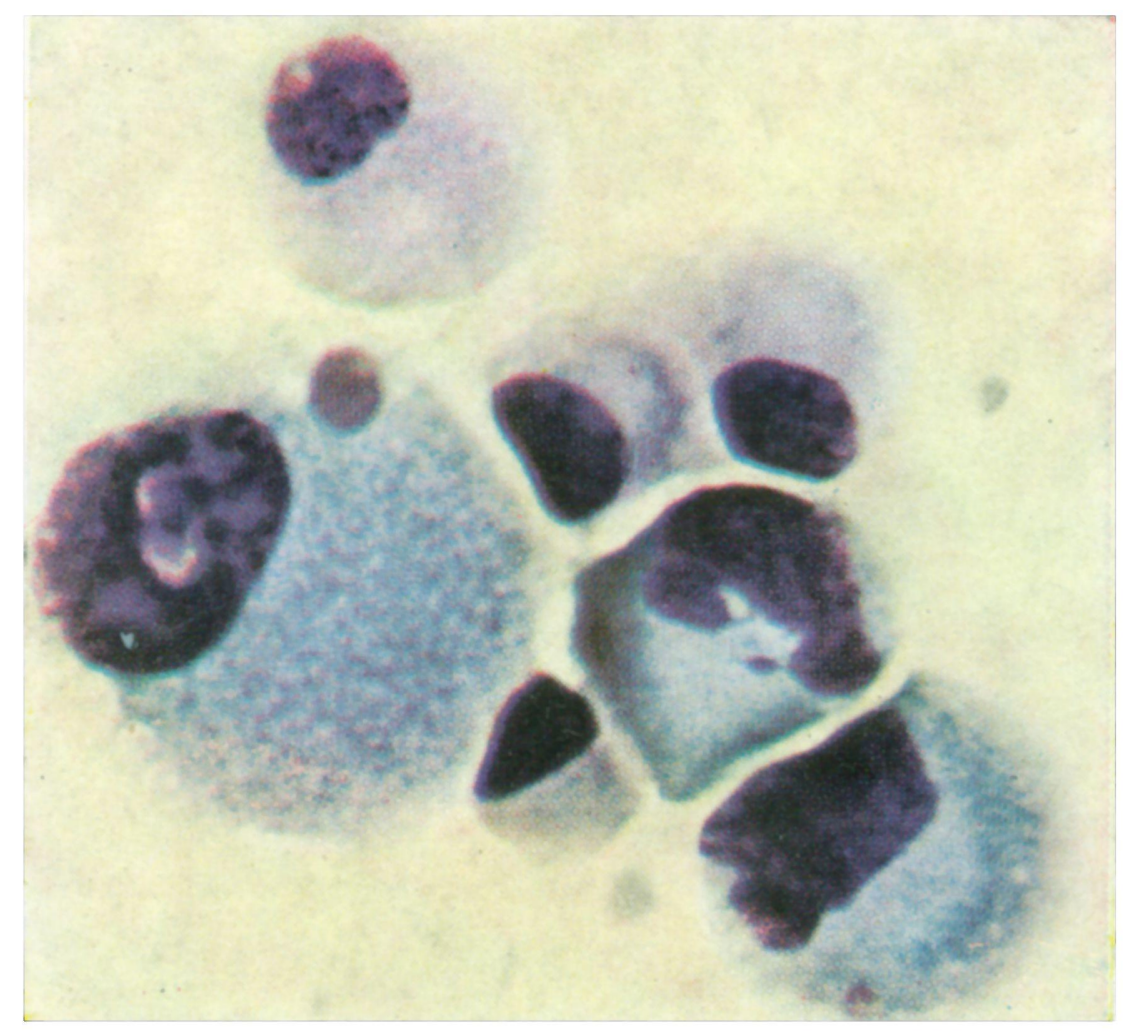

Fig. 3-Agrupamento de células melanomatosas. Notar, no citoplasma, granulaç̃o escura $e$ fina (May Grünwald-Giemsa $360 x$ ).

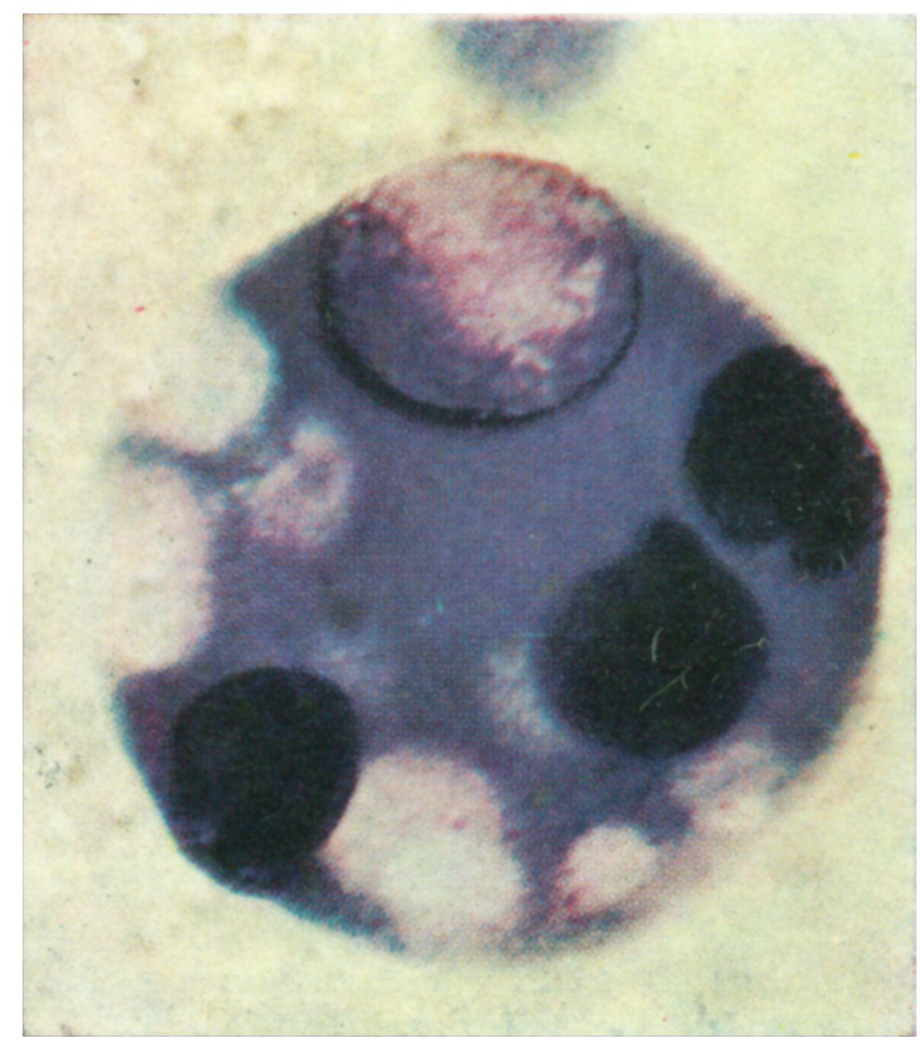

Fig. 4-Célula melanomatosa gigante, polinucleada. Notar vacuolos citoplasmaticos (May GrinwaldGiemsa $360 x$ ). 

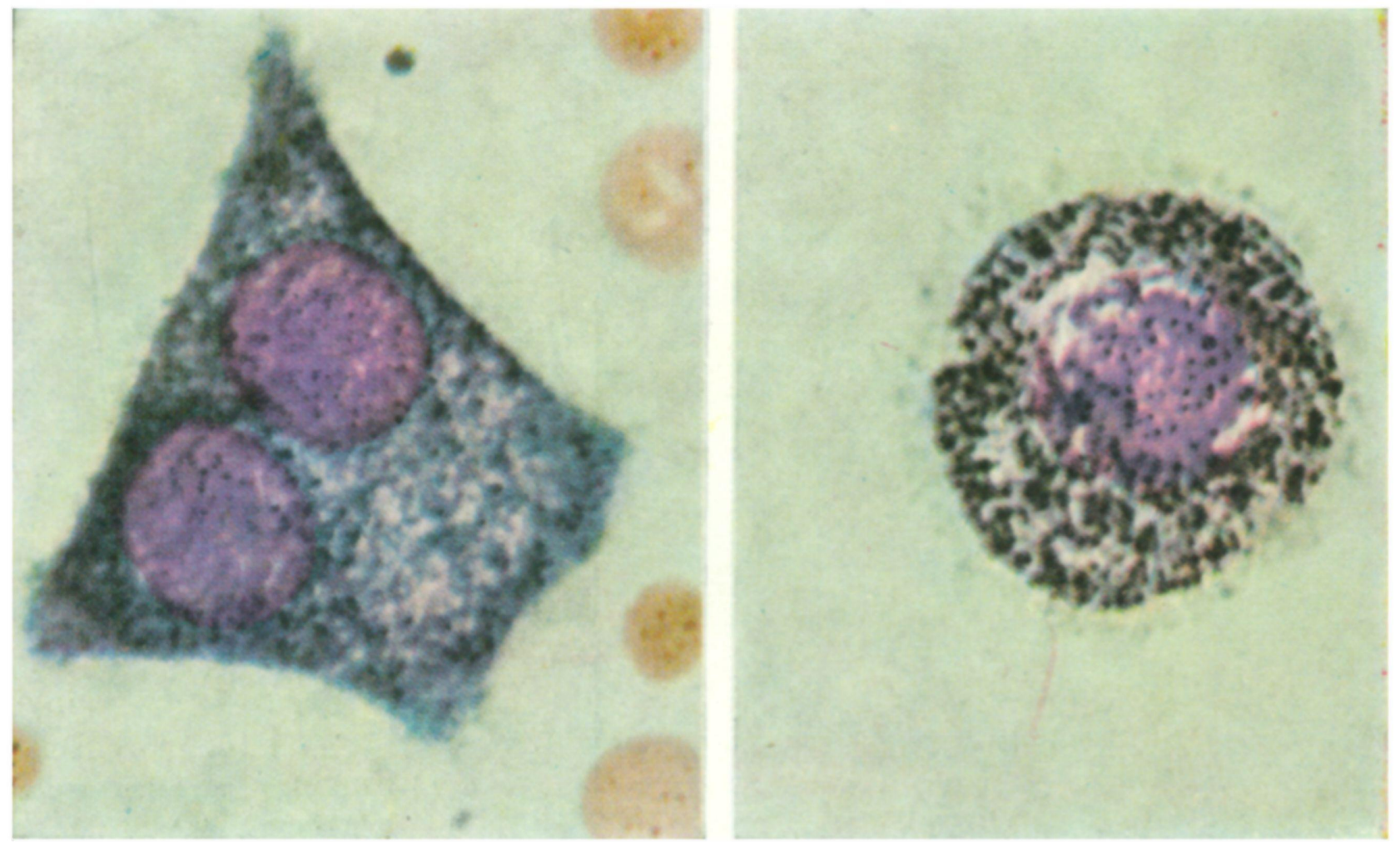

Frig. 5-A esqucrda célula binucleada com aspecto epitelioide. (May Grünwald-Giemsa 560x). A direita, célula melanomatosa isolada contendo pigmento de textura varidvel; contorno celular apresentando grande núméro de projeçes (Leishman 560x).
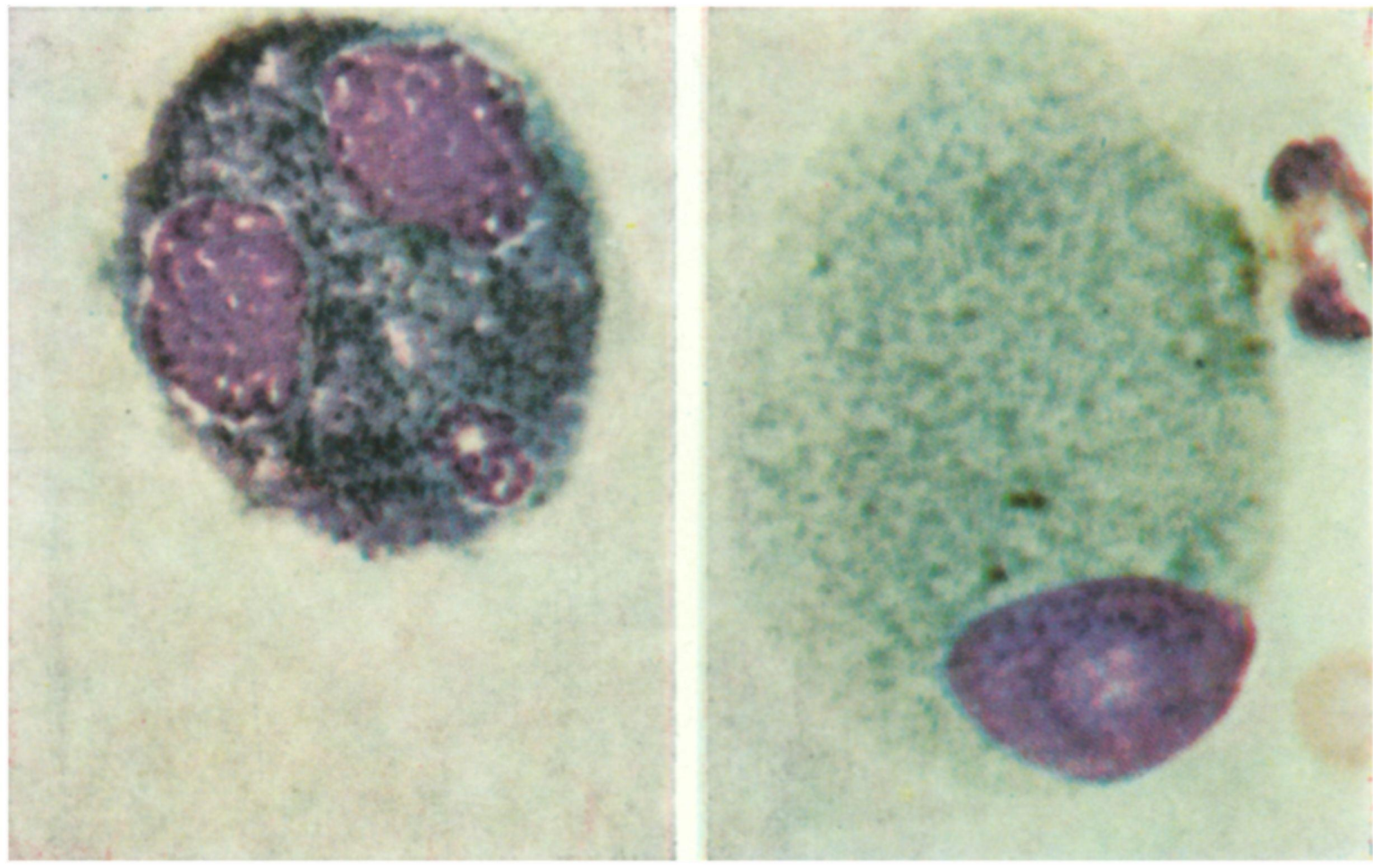

Irig. 6 - a esquerda célula melanomatosa polinucleada contendo grande quantidade de pigmento (May Grünwald-Giemsa 560x). A direita, célula melanomatosa gigante; nnicleo denso, com nuclélo evidente (Leishman 560x). 
12 ARQ. NEURO-PSIQUiATRIA (SAO PAULO) VOL. 37, No 1, MARGO, 1979

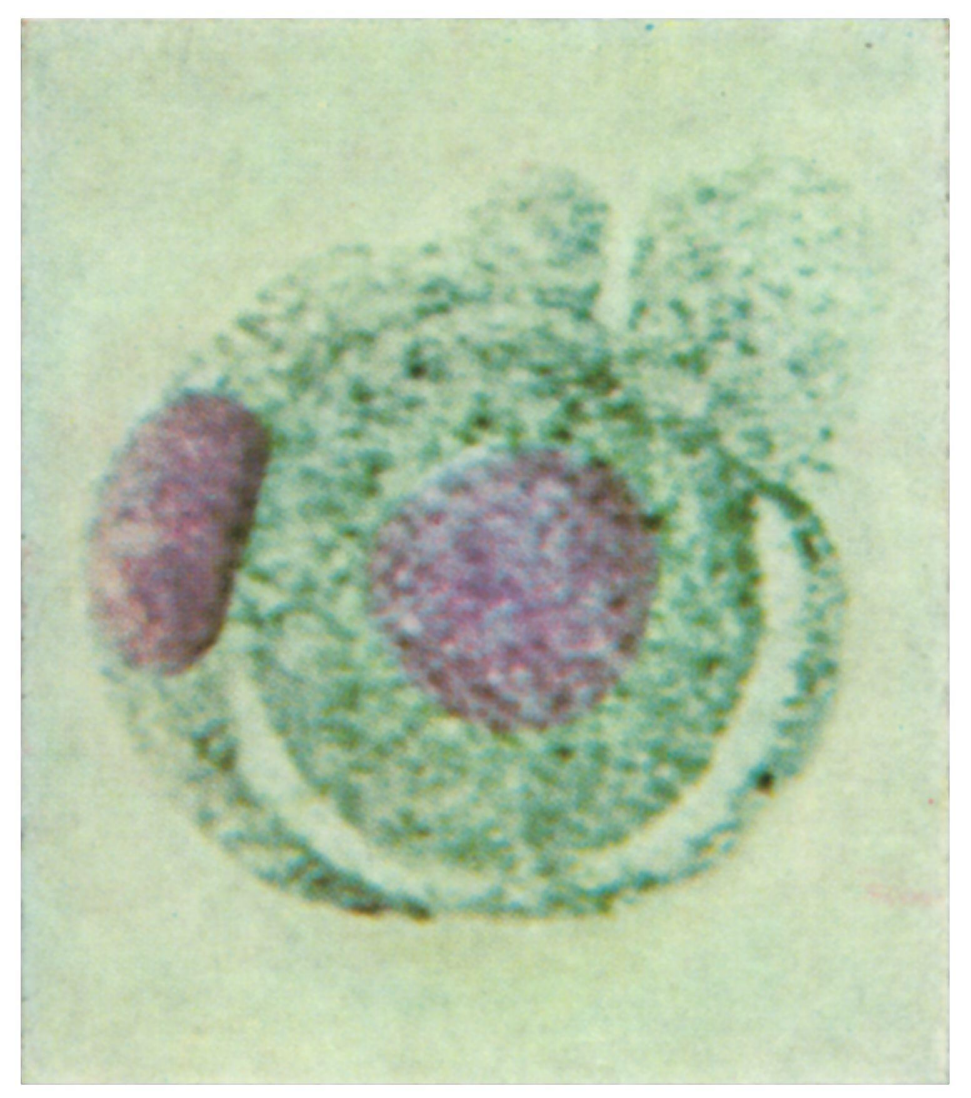

Fig. 7-Células melanomatosas justapostas (Leishman $560 x)$.

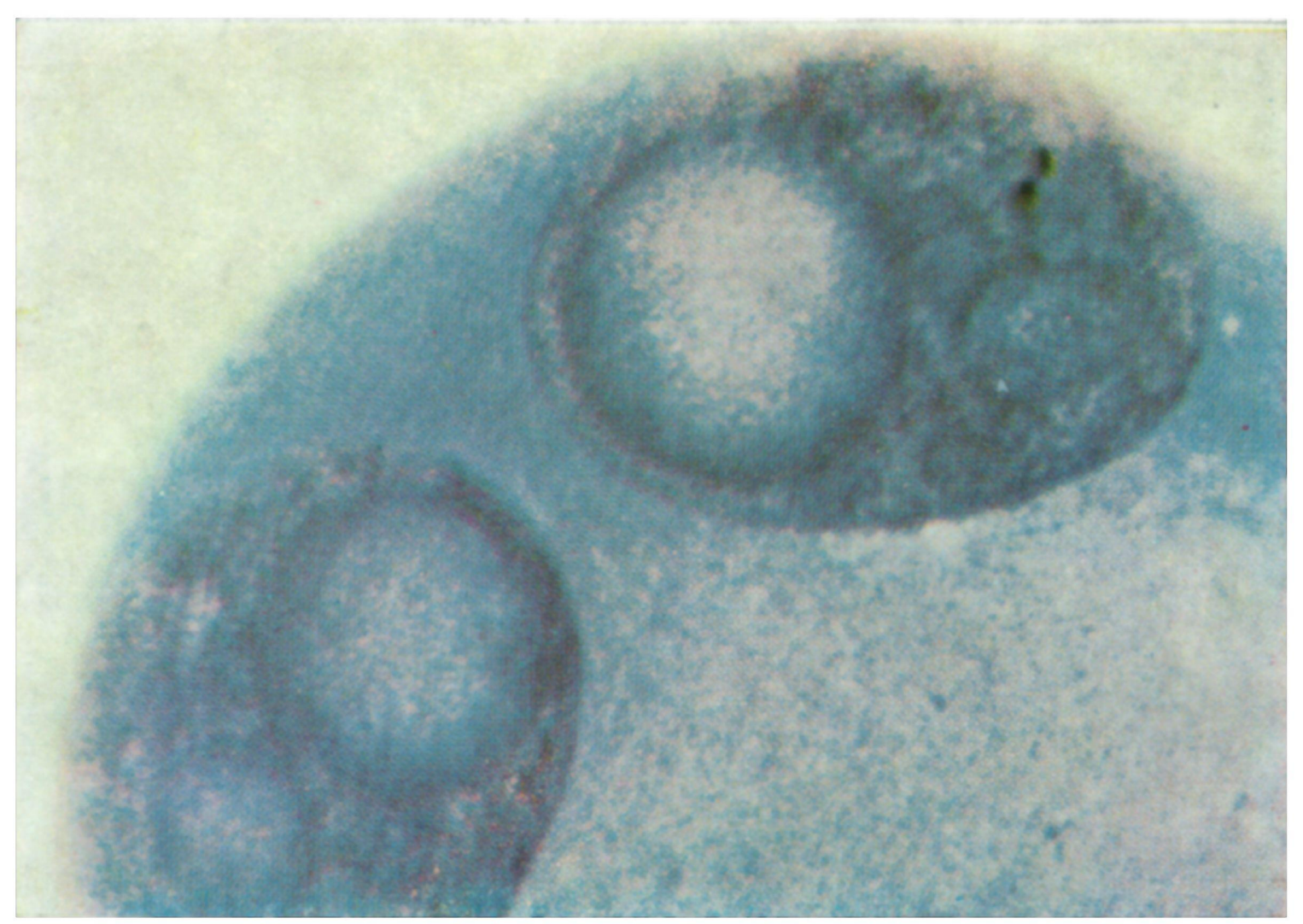

Fig. 8 -Detalhe de célula melanomatosa multinucleada gigante. Núcleo contendo grandes nucleolos (May Grïnwald-Giemsa 560x). 
em nosso meio 0. As preparações assim obtidas foram coradas pelo método de May Grünwald-Giemsa ou pelo de Leishman e eventualmente pelo azul da Prússia. A análise citomorfológica toi efetuada mediante optomicroscopia.

\section{ANALISE CITOMORFOLOGICA}

Em todos os pacientes, a citomorfologia do LCR tem caracteristicas semelhantes, razăo pela qual a descrição é feita em conjunto.

De permeio a linfócitos, reticulomonócitos, neutrófilos, eosinófilos e macrófagos elementos pertencentes às classes I e II 10 - são encontradas células atípicas ao LCR. Estas apresentam tamanhos e formas variadas (figuras 1 a 8 ). A visão panoramica da lâmina permite o reconhecimento de células isoladas ou agrupadas, em geral grandes, por vezes semelhantes em tamanho e forma aos macrófagos. Os agrupamentos ocorrem com frequência inconstante, quase sempre por justaposiçáo de células isoladas, dificilmente mostrando formações sinciciais, tão frequentes em outras neoplasjas. Aparecem, por outro lado, células gigantes, às vezes, multinucleadas ou apresentando condensações grosseiras de cromatina esparsas no citoplasma.

Em todas as lâminas analisadas a relação núcleo-citoplasma está relativamente conservada, tendendo nas células maiores a uma diminuição proporcional da massa nuclear. Os limites do núcleo usualmente são bem definjdos, aparecendo com alguma frequência um halo claro perinuclear.

O material nuclear apresenta-se bastante compacto e a cromatina forma condesações de textura variável desde formaçóes irregulares e grosseiras, que predominam, até figuras de cromatina mais trouxa de aspecto reticulado. A presença de nucléolos é comum; eles em geral são grandes, bem delimitados e por vezes múltiplos, chegando a ocupar em algumas células, a maior parte do núcleo. Figuras de mitose são bastante frequentes, algumas assumindo formas bizarras, tanto no que diz respeito à disposiçåo da cromatina e do fuso como no que tange à sua distribuiçăo na célula. O citoplasma é bem definido chamando imediatamente atenção, a presença de grande quantidade de pigmento castanho-escuro. Este é constituido de granulações finas, arredondadas, de tamanhos variáveis, mas forma relativamente constante. Esta caracteristica tende a mascarar todo o restnte da estrutura citoplasmática e mesmo nuclear embora sejam perceptíveis algumas vezes vacúolos bem delimitados e uma basofilia de intensidade variável, que contribuem para a aparência francamente maligna da célula como um todo. Tal pigmento aparece também em macrófagos, por vezes com a textura já descrita, outras vezes formando granulaçós mais grosseiras e irregulares semelhantes às do pigmento hemossiderótico.

Considerando-se que os melanomas são tumores que facilmente provocam hemorragias no espaço subaracnódeo, torna-se extremamente importante o uso de coloraçăo especifica para o ferro, pois permite demonstrar a presença dos dois pigmentos nos macrófagos, geralmente. O restante da população celular pertence às classes I e II mostrando sinais evidentes de ativaçáo. mas sem qualquer outra caracteristica especifica.

\section{COMENTARIOS}

Os dados encontrados nos casos ora relatados coincidem com aqueles referidos na literatura ${ }^{1,5,6, \pi, 8,11,12}$, tanto no que se refere às células atípicas ao LCR, como no que diz respeito às células pertencentes as classes I e II ${ }^{10}$, inclusive quanto à presença de eosinófilos ${ }^{4}$, verificada em um dos casos.

$O$ diagnóstico da melanomatose meníngea é feito com segurança através da análise citomorfológica. Isto torna-se evidente considerando que em três dos pacientes aqui apresentados a suspeita clínica era diversa, e o diagnóstico foi firmado pela citomorfologia do LCR e confirmado anatomo-patologicamente (casos 2, 4 e 6). 
A possibilidade de ocorrência de melanomatose meningea secundária, evidenciada na casuística relatada, deve ser investigada sempre que possível. Esta investigação é efetuada mediante o estudo da citomorfologia do LCR e deve ser feita precocemente. A precocidade e mesmo investigações repetidas, podem conduzir ao diagnóstico em fases iniciais, abrindo novas perspectivas à abordagem terapêutica e a estudos da imunobiologia do acometimento leptomeníngeo nos melanomas.

\section{RESUMO}

Meningeal melanomatosis: cytomorphological analysis of cerebrospinal fluid.

Six cases of meningeal melanomatosis are reported. The cytomorphological analysis of cerebrospinal fluid lead to diagnosis in all of them. Emphasis is given to morphological characteristics of the tumor cells and specially to the melanin dark brown pigment, observed in all cases here reported.

\section{REFERENCIAS}

1. BUDKA, H. \& SUMMER, K. - Liquorzellbefunde bei primärer diffuser melanvblastose der meningen. Arch. Psychiat. Nervenkr. 217:329, 1973.

2. DUFresne, J. J. - Citologia Prática del Liquido Cefalorraquídeo. Documenta Geigy. Ed. Ciba Geigy, Basiléa, 1972.

3. HAJDU, S. I. - Cytologic diagnosis of malignant melanoma. Acta Cytol. (Baltimore) 16:70, 1972

4. KOLAR, O. \& ZEMAN W. - Spinal fluid cytomorphology. Arch. Neurol. (Chicago) $18: 44,1968$.

5. KOLMEL, H. W. Atlas of Cerebrospinal Fluid Cells. Springer Verlag, Berlin, 1976.

6. OEHMICHEN, M. - Cerebrospinal Fluid Cytology. W. B. Saunders Co. (Philadelphia) \& Georg Thieme Publ. (Stuttgart), 1976.

7. OLISCHER, R. M. \& SCHROTER, P. - Zur Diagnostik der primären Melanoblastomatose des zentral Nervensystems. Nervenarzt 34:266, 1963.

8. SAYK, J. - The cerebrospinal fluid in brain tumors. In P. J. Vinken \& G. W. Bruyn - Handbook of Clinical Neurology, 16:360, North Holland Publ. Co., Amsterdam, 1974.

9. SPINA-FRANÇA, A. - Câmaras de sedimentação no estudo citológico do líquido cefalorraqueano. Arq. Neuro-Psiquiat. (São Paulo) 28:84, 1970.

10. SPINA-FRANÇA, A.; MACHADO, A. B. B. \& PASQUALIN, J. R. - Técnica de Suta e identificação de células neoplásicas no líquido cefalorraqueano. Arq. Neuro-Psiqujat. (São Paulo) 29:463, 1971.

11. SPRIGGS, A. I. \& BODDINGTON, M. M. - The Cytology of Effusions. Grune \& Stratton Inc., New York, Ed. 2, 1968.

12. TOURTELLOTE, W. W. - Neoplastic cells in the cerebrospinal fluid; report of a case of metastatic melanoblastoma. Neurology (Minneapolis) 13:866, 1963.

Centro de Investigaços em Neurologia - Caixa Postal 5199 - apooo são Paulo, $S P$ - Brasil. 